\title{
As tentativas dos cognitivistas pioneiros
}

\author{
Reinier Johannes Antonius Rozestraten \\ Universidade Católica Dom Bosco
}

\begin{abstract}
Resumo
O presente artigo pretende dar informações precisas sobre Oswald Külpe e sua aplicação do método experimental aos processos cognitivos. Como pensamos? As imagens perceptivas sempre são necessárias para desenvolver um pensamento? Qual a rapidez com que pensamos e como resolvemos problemas? Com o auxílio de seus alunos, dos quais vários se tornaram eminentes psicólogos, aperfeiçoou os métodos de observação e a análise dos resultados. Antes de aderir definitivamente à Psicologia, ficou dividido entre a História e a Psicologia e, apesar de usar métodos experimentais, considerou a Psicologia uma área pertencente à Filosofia. Na sua conferência de 1912, apresentou, como síntese, a existência de pensamentos sem conteúdos perceptivos, que o Eu desempenha um papel central no pensamento e que há, na solução de problemas, uma tendência dominante da tarefa. Depois de Würzburg, as escolas de Colônia, Mannheim e Amsterdã continuaram as pesquisas com novas abordagens em crianças surdo-mudas, descobrindo níveis na consciência e aplicando os novos conceitos sobre o pensamento e a solução de problemas ao ensino da escola fundamental. Foi, principalmente, este último ponto, o mais desenvolvido por Kohnstamm, acentuando a prática da leitura silenciosa como uma maneira para o pleno desenvolvimento das capacidades intelectuais das crianças.
\end{abstract}

Palavras-chave: pioneiros cognitivistas; influência da Escola de Külpe; início do cognitivismo

\begin{abstract}
The tentatives of the pioneer cognitivists. This paper intends to offer more exact information about Oswald Külpe and his application of the experimental method on cognitive processes. How do we think? Are perceptive images always necessary to create our thinking? What is the speed of our thinking and how do we solve problems? With the support of his students - several of them were to be eminent psychologists - he improved the methods of observation and the analysis of the results. Before joining definitively psychology, for a long time he was divided between history and psychology and even using experimental methods considered psychology as belonging to the area of philosophy. In his conference of 1912, he presented as a synthesis the existence of imageless thinking, the central role of the Ego in thinking activity and the dominant tendency of the thinking task in problem solving. After Würzburg the schools of Colonia, Mannheim and Amsterdam continued the studies with new approaches for deaf-mute children education, discovering levels of conscience and the application of the new concepts about thinking and problem solving in primary school teaching. It was mainly this last point that was further developed by Kohnstamm emphasizing the practices of silent reading as a method to reach the full development of intellectual capacities of children.
\end{abstract}

Key-words: pioneer cognitivists; influence of Külpe’s school; start of cognitivism

$\mathrm{P}$ retendemos, no presente artigo, apresentar um recorte histórico a respeito das primeiras tentativas de Oswald Külpe e sua Escola em Würzburg para pesquisar os elementos e os processos cognitivos pelo método experimental. Esse recorte abrange o último decênio do século XIX e os três primeiros decênios do século XX, mostrando a influência dos novos conceitos adquiridos e ampliados pelas esco- las de Colônia, Mannheim e Amsterdã na Pedagogia e na Didática nas escolas primárias e secundárias da Alemanha e da Holanda.

Foi em 1862 que nasceu Oswald Külpe, em Candau na Letônia, uma região da Rússia perto do Leste da Prússia. Apesar disto, ele se identificou mais com a Alemanha. Seu pai era tabelião. Oswald cursou seu ginásio em Libau, na costa 
báltica de Cowland. Logo depois já começou a dar aula como professor particular e, com 19 anos, entrou na Universidade de Leipzig, para estudar história.

\section{História ou Psicologia Experimental?}

Em contato com Wundt, Oswald se desviou para a Filosofia e para a Psicologia experimental no laboratório de Wundt, que existia apenas há dois anos. Oswald trabalhou um ano com Wundt; no entanto, parece não ter ficado convencido de sua direção de estudo e mudou-se para Berlim, a fim de novamente estudar História. Lá, ele teve contato com grandes historiadores, como Mommsen, Kirchhoff e Dick. Novamente, não convencido de sua vocação de historiador, foi trabalhar com G. Müller, em Göttingen, onde começou sua tese de doutoramento sobre os sentimentos, um estudo teórico do mesmo tipo que Müller tinha elaborado sobre a atenção.

Quando publicou, posteriormente, sua tese em Leipzig, mencionou seu reconhecimento a Müller e não a Wundt. Mesmo após este doutoramento, ficou de novo tentado pela História. Deixou Müller e foi para Dorpat, onde estudou mais um ano História.

\section{Período no Laboratório de Wundt}

Finalmente, em 1886, resolveu voltar para o laboratório de Wundt em Leipzig, onde ficou por oito anos, quando se transferiu, em 1894, para Würzburg. Um ano depois, em 1887, defendeu sua tese Sobre a teoria dos sentimentos sensoriais. No ano seguinte, tornou-se docente e também assistente de Wundt. Trabalhou nos seus experimentos e, também, ajudando os outros. Vários desses experimentos tratavam da cronometria mental. Em 1891, publicou um importante artigo sobre o tempo de reação bimanual mostrando que a mão sobre a qual se dirige a atenção é a mais rápida.

Wundt, apesar de ter criado o método experimental, tinha-o restringido à percepção, à imaginação, à memória e ao tempo de reação; aquilo que ele qualificava como processos psicológicos inferiores, julgando que os processos psíquicos superiores, como pensamento, raciocínio lógico, normas morais, não podiam ser estudados pelo método experimental, mas pela observação e estudos antropológicos de hábitos e formas de moral nos diferentes povos.

Külpe, naquele tempo, estava pensando no projeto de um manual de Psicologia, no qual pretendia apresentar somente os resultados da aplicação do método experimental, restringindo-se apenas àquilo que era experimentalmente verificado. Este livro Fundamentos da Psicologia (Grundriss der Psychologie) veio à luz em 1893, e, de fato, restringiu-se aos resultados dos experimentos, deixando de lado as especulações e reflexões de Wundt, apesar de dedicar o livro a ele. Külpe definiu a Psicologia como a "ciência dos fatos da experiência”. Grande parte deste livro trata das sensações, mencionando, no entanto, também os trabalhos de Ebbinghaus sobre a memória, o trabalho de Wundt sobre a teoria tridimensional dos sentimentos e sobre os diversos tipos de associações, introduzindo o termo coligação para as formas de combinações espaciais e temporais. Tratou, também, da atenção, da vontade e da autoconsciência; porém ainda não falou sobre os experimentos com o pensamento.

\section{O período em Würzburg}

Logo após a publicação de Fundamentos da Psicologia, Külpe foi promovido a docente extraordinário na própria Universidade de Leipzig. Mas, tendo em vista terem lhe oferecido um lugar de catedrático na Universidade de Würzburg, ele mudou-se para lá antes do final de 1894. Apesar de seu grande trabalho ser sobre o pensamento sem imagens, ele publicou primeiro uma Introdução em Psicologia no mesmo estilo dos Fundamentos da Psicologia. O livro teve um sucesso enorme e conseguiu sete edições; foi traduzido, assim como os Fundamentos, para o inglês por Titchener, seu antigo colega no laboratório de Wundt. Escreveu, em 1897, um artigo sobre a atenção e, em 1902, outro sobre a Psicofísica. Ao mesmo tempo, publicou artigos filosóficos sobre "A filosofia da atualidade na Alemanha”, seguido por um tratado sobre Emanuel Kant. No mesmo ano, ele já estava realizando seus experimentos sobre a abstração.

Uma vez que a Estética, com destaque para a música, fazia parte dos seus interesses dominantes, escreveu e publicou, em 1903, numa edição do American Journal of Psychology, um artigo sobre a Estética experimental em homenagem a Stanley Hall.

Muito embora na primeira década do século XX ele tivesse se ocupado mais com Filosofia e Estética, seu laboratório editou vários trabalhos experimentais sob sua permanente orientação. Funcionava como sujeito e experimentador em muitos desses experimentos. No entanto, naquela época, ainda não era capaz de sintetizar os resultados numa teoria bem construída. Os trabalhos de seus alunos têm muitas de suas convicções uma vez que todos foram orientados por ele.

\section{Trabalhos sobre o pensamento}

O primeiro trabalho sobre o pensamento foi o artigo publicado em 1901 por Mayer e Orth sobre a natureza qualitativa da associação. O pensamento está no âmbito da associação. Por que então não descrever ou pedir para descrever os pensamentos que as pessoas têm? Conforme a convicção positivista de Külpe, a ciência tem de ser empírica e seu método deve ser o da observação e descrição.

Foi no mesmo ano de 1901 que Marbe realizou seu experimento sobre o julgamento comparativo de peso. $\mathrm{O}$ sujeito tinha de levantar dois pesos julgando sua diferença e dizer qual era o mais pesado e, também, como havia chegado a essa conclusão. Apesar de ter sensações de tato, de cinestesia e imagens dentro de uma extensão temporal, a introspecção não revelou "condições psicológicas do julgamento”. O julgamento simplesmente se apresenta e, na maioria das vezes, está correto. Mas o sujeito não sabe dizer como ele fez para pensar que um peso era mais pesado do que o outro. Isto, sem dúvida, foi uma novidade, pois esse fato parecia contrariar o que durante séculos se tinha como ponto pacífico, que as leis da lógica são as leis do pensamento. O processo do pensamento estaria definido no próprio silogismo. 
Verificou-se, então, através do método introspectivo, que a mente seguia uma série irracional e associativa de conteúdos mentais e mesmo assim chegava a uma conclusão não apenas racional, mas, na maioria das vezes, perfeitamente em acordo com a realidade física. Os sujeitos de Marbe foram excelentes introspeccionistas como Mayer, Orth e o próprio Külpe. No entanto, como Boring sugere, é possível que nem tudo o que passou por suas consciências passou para os relatórios.

A reflexão sobre estes fatos fez surgir um problema: se as sensações e imagens que sempre aparecem na introspecção não aparecem, que outro conteúdo deve existir na consciência que dá conta do pensamento? Marbe introduz a palavra "Bewustseinslage", que pode ser traduzida como nível de consciência ou atitude de consciência; Boring prefere falar simplesmente em "pensamento não-consciente".

Dois anos depois, Orth trabalhava sobre o sentimento e não sobre o pensamento. Ele teria de aceitar a nova teoria tridimensional de Wundt sobre a multiplicidade de sentimentos, aceitando além dos opostos agradável-desagradável, também o tenso-relaxado, a excitação-calma e suas combinações. Além disso, deveria aceitar que a mente tivesse um conteúdo afetivo maior que o sensorial ou, então, deveria inventar outra hipótese. Orth então achou que estes sentimentos de Wundt poderiam ser na realidade as atitudes conscientes, conteúdos obscuros que não se deixavam descrever em termos sensoriais nem conceptuais.

Nesta classificação, ele procurou, conforme Boring (1950), incluir "muitos dos sentimentos wundtianos, os de consciência de James e a qualidade de familiaridade de Höffding” (p. 403).

Outro aluno de Külpe era Watt que, em 1904, começou a investigar o próprio pensamento. Seus sujeitos tinham de seguir instruções que pediam associações mais delimitadas, solicitando deles o supra-ordenado de uma parte, por exemplo: folha - (galho); e o infra-ordenado de um todo, por exemplo: casa - (janela). Apesar de não ter resolvido o problema do pensamento, constatando a pobreza dos dados da consciência na realização do pensamento, Watt tem o mérito de ter introduzido três modificações metodológicas:

1. Usou o cronoscópio de Hipp, capaz de indicar o tempo de reação em milésimos de segundo, apesar de ser um instrumento apenas mecânico. Era uma tentativa de precisão na medição do tempo do pensamento. Infelizmente ele não o conseguiu.

2. Introduziu o fracionamento do tempo de introspecção. Às vezes, o sujeito pode usar muitas palavras; porém, enquanto fala, sua memória daquilo que observou vai enfraquecendo. Por isto Watt dividiu o total da observação em quatro períodos: (a) o período de preparação, (b) a apresentação da palavra estímulo, (c) a procura da palavra-reação e (d) a chegada da palavra-reação. Seus sujeitos deveriam concentrar-se sucessivamente em cada um destes períodos.

3. Deu muita importância à tarefa. Apesar de todos acharem que o dado mais importante para o pensamento seria achado no terceiro período, Watt chegou à conclusão de que o pensamento começava a se desenvolver a partir da boa compreensão da tarefa no primeiro período. Portanto, antes de saber sobre o que exatamente se deveria pensar, a indicação do tipo de pensamento já começava a agir com um conteúdo mínimo. As tarefas foram de diversos tipos, porém, a palavra tarefa entrou na Psicologia como "um conceito fundamental introspectivo”. A tarefa já indica a direção em que o pensamento tem de se desenvolver, provocando uma atitude preparatória, como a de um corredor no momento do início. Otto Selz desenvolveria depois as idéias de Watt.

Outro colaborador e aluno de Külpe foi Narziss Ach, anteriormente assistente de G. E. Müller, em Göttingen, de 1901 a 1904. Trabalhou em 1905 sobre ação e pensamento. Seu trabalho é mais conhecido do que o de Watt, em parte porque conseguiu formular melhor os resultados aos quais Watt tinha chegado. Também ele usou o cronoscópio de Hipp e reviu vários trabalhos sobre o tempo de reação. Através de seu trabalho ficou claro que "os problemas do pensamento e de ação são essencialmente os mesmos” (Boring, 1950, p. 404). Em ambos, há um alvo a ser alcançado, e o processo psicofísico que é iniciado pelo estímulo se desenvolve na direção do alvo. Achar uma rima para uma palavra-estímulo não é psicologicamente diferente de pressionar com certo dedo quando aparece determinada letra.

Ach tomou três posições importantes:

1. Deu ao método de fracionamento de Watt o nome oficial de introspecção experimental sistemática referindo-se a uma técnica científica cuidadosa, incluindo também o uso do cronoscópio e outros instrumentos de precisão.

2. Introduziu o termo tendência determinante, uma tendência que Watt já havia observado e que procurou explicar pelas tendências preservativas de Müller. Uma tentativa para explicar a maneira como a tarefa inicial caminha de maneira inconsciente para o alvo pretendido. O conceito tendência determinante implica que ela funciona como um comando superior reforçando certas tendências associativas. Assim quando se oferece um 5 escrito e um 2 abaixo dele, as associações podem ser 7 ou 3 ou 10, conforme se supõe as operações somar, subtrair ou multiplicar. O comando somar reforça a associação 7, que se torna o mais forte, provocando a resposta. Ach tornou esta relação entre a preparação e a tarefa cumprida mais real dando-lhe um nome. No entanto, a tendência determinante também foi aceita por oponentes da Escola de Würzburg e foi considerada um processo fisiológico, mesmo que, como Boring enfatiza, a única coisa que a torna fisiológica é o fato de não ser consciente. Desta forma, a Escola de Würzburg toma uma posição na psicologia da atitude.

3. Inventou o termo Bewustheit, portanto diferente da consciência. Bewustsein, assim como Bewustseinslage, indica um conteúdo consciente vago e intangível que não é imagem ou sensação. A tradução poderia ser 
conscientado ou não-perceptivo. É provável que quase não exista diferença entre a atitude consciente de Orth e o Bewustheit de Ach. Merece menção que Ach, além de se interessar pelo pensamento, também estudou intensamente a vontade. Na realidade, suas pesquisas já tinham começado em 1900 orientadas por G. E. Muller, em Göttingen, e terminaram em 1904, em Würzburg. Em 1905, publicou seu livro Ueber die Willenstätigkeit und das Denken (Sobre a atuação da vontade e o pensamento) antes da publicação do artigo de Watt, dedicando-o a seus dois mestres: G. E. Müller e Oswald Külpe. Ficou claro, aos poucos, que o pensamento não estava necessariamente ligado a dados sensoriais.

Naquele mesmo ano de 1905, Messer de Giessen passou a integrar a Escola de Würzburg. Ele continuou trabalhando com o método de introspecção experimental sistemática. No seu artigo final procurou classificar os dados conscientes, porém não foi uma contribuição importante para as teses da Escola. Foi o primeiro da Escola a citar Hüsserl, cujo Logische Untersuchungen (Pesquisas lógicas) tinha sido publicado em 1900-1901.

Um dos últimos orientandos de Külpe foi Karl Bühler, que veio de Berlim em 1907, e que publicou, em pouco tempo, três artigos sobre a Psicologia dos processos de pensamento. O método usado por ele, Ausfragemethode, era bem diferente do questionário mais rígido da Aussagemethode. $\mathrm{O}$ experimentador conversava com o sujeito, havia uma comunicação livre e aberta a sugestões que poderiam ser úteis na psicanálise, mas que não foi bem recebida pelos defensores da introspecção experimental sistemática e que fugiu de uma descrição rigorosa dos processos mentais.

Foi muito criticado por Wundt, por Düss e por von Áster. Isto não o impediu de ser, mais tarde, um dos pioneiros da Psicologia da Criança. Na sua obra principal Die geistige Entwicklung des Kindes (O desenvolvimento psíquico da criança), tratou amplamente do desenvolvimento do pensamento da criança. Distinguiu dentro desse desenvolvimento, três fases, a saber, a do instinto, a do adestramento e a do intelecto.

\section{A conferência de 1912}

Quando Külpe se transferiu para Bonn, em 1909, praticamente teve fim a Escola de Würzburg. Interessado na relação entre Psicologia e Medicina, suas publicações lhe conferiram, em 1907, o título honorífico de médico da Universidade de Giessen.

Em 1912, ao lado da publicação sobre este tema, Külpe proferiu uma conferência Ueber die moderne Psychologie des Denkens (Sobre a psicologia moderna do Pensamento), na qual apresentou um resumo dos principais resultados da Escola de Würzburg.

\section{Existem conteúdos na consciência que são não- perceptivos.}

A Psicologia antiga, incluindo a doutrina associativa e a teoria de Herbart, aceitava que todos os conteúdos psí- quicos se baseiam em impressões sensoriais. Na base do empirismo de John Locke, somente se aceitavam percepções e imagens, ou elementos perceptivos; toda a vida psíquica era construída por meio deles. Idéias e conceitos seriam apenas imagens mais genéricas, mais diluídas, mais finas, porém sem diferença essencial com as imagens individuais. $\mathrm{O}$ pensamento seria, então, uma corrente de imagens que obedecia cegamente às leis de associação. Certas imagens chamavam outras até se alcançar a solução do problema. Os pesquisadores da Escola de Würzburg tinham provado experimentalmente que, na consciência, não existem somente sensações, percepções e imagens, mas há também elementos que são essencialmente não-perceptivos, os Bewustheiten de Ach. É perfeitamente possível ver relações e conexões sem encontrar elementos perceptíveis. Pode-se até dizer que o essencial do pensamento consiste exatamente no não-perceptivo. As imagens no pensamento ocupam um lugar apenas secundário. Pensamento é um fenômeno abstrato e de maneira alguma poderá ser reduzido a uma corrente de imagens.

Külpe e seus orientandos mostravam a seus sujeitos experimentais algumas palavras dando-lhes a tarefa de achar um conceito superior ou inferior. Esses, nos seus relatos de introspecção experimental sistemática, declaravam que a leitura ou o som dessas palavras não lhes provocava imagens perceptivas. Se alguma imagem aparecia, era vaga e de curta duração. Külpe também apresentava tarefas sem nenhum conteúdo perceptivo, como: “tente compreender a frase 'pensar é tão extremamente difícil que muitos preferem simplesmente julgar’...”. Pensar não-perceptivamente é algo comum, como testemunhou um sujeito de experimento: “fora das palavras na frase que ouvi e reproduzi não havia nada perceptivo na consciência” (Palland, 1961, p. 393).

Apesar da oposição de G. E. Muller, os experimentos dos pesquisadores de Würzburg apontavam na mesma direção e aos poucos começou a ser mais aceito o fato de que na vida psíquica existem elementos não-perceptivos, os fenômenos de pensamento.

\section{Nos fenômenos do pensamento a atividade do Eu desempenha um papel importante.}

A Psicologia antiga era uma Psicologia do conteúdo, estudava os conteúdos da consciência como dados passivos. O Eu era visto como algo passivo que podia possuir esse ou aquele percepto ou imagem. No entanto, os protocolos dos pesquisadores de Würzburg mostravam que as pessoas tinham uma forte impressão de ação, a nítida vivência de uma atividade. Eles mostravam constantemente que na consciência se efetuam ações, o que na Psicologia antiga não tinha sido percebido. Em conseqüência disso, Külpe colocava o Eu em primeiro lugar, como em "Die monarchische Einrichtung unseres Bewustseins tritt zutage. Da Ich sitzt auf dem Thron und vollzieht Regierungsakte” (A organização monárquica da nossa consciência se manifesta. $\mathrm{O}$ Eu está sentado no Trono e realiza os atos governamentais.) (citado por Palland, 1961, p. 393). Ou, por outro lado, mesmo não mencionado por Külpe podemos ver aqui também uma influência do funcionalismo americano, não interessado nos 
conteúdos, mas nas funções e na finalidade das capacidades psíquicas.

\section{O pensamento é dominado por uma "tendência dominante", a tarefa do pensamento.}

Enquanto a Psicologia associacionista explicava o pensamento como uma corrente de imagens, dominada pelas leis associativas e reprodutivas, a Escola de Würzburg rejeitava este mecanismo. Para seus adeptos, o pensar tem um caráter teleológico, corre numa certa direção procurando uma solução. O problema proposto ou a tarefa de pensar determina a direção do pensamento. Qualquer tarefa aceita pelo Eu exerce uma influência determinante e reguladora sobre a atividade psíquica. A tendência determinante, para Ach, é uma intencionalidade, um estar-orientado-interior para a solução. Esta tendência, por um lado, indica o alvo e, por outro, também determina o termo do processo do pensamento. Podemos ver que, anos depois, Allen Newell com suas pesquisas do pensamento por computador aceita praticamente esta tendência determinante, procurando as etapas intermediárias da solução de problemas.

O pensamento em si é algo abstrato; apesar de ser um processo consciente, ele recebe sua força e sua direção da tarefa de pensar, ou o problema a resolver indica o caminho. Porém, cada um vê o problema e seu contexto dentro de sua vivência pessoal. Por exemplo: compare os processos de pensamento de um arqueólogo, um bombeiro, um demolidor, um restaurador, um urbanista que partem da constatação: "Paris possui muitos edifícios velhos”.

\section{Os últimos anos de Külpe em Bonn}

Eram principalmente os problemas filosóficos que o interessavam e a relação Psicologia - Medicina. Publicou diversos artigos sobre epistemologia, ciências naturais, o conceito de realidade e a doutrina de categorias (Boring, 1950, p. 407). Publicou seu livro mais importante, Die Realisierung, (A Realização) em 1912, um estudo filosófico sobre a realidade, mas ficou claro que ainda não estava pronto para dar um fecho na Psicologia do pensamento.

Lecionava Psicologia e através da preparação de suas aulas estava preparando uma nova edição dos seus Fundamentos. Conforme Flugel, "os Fundamentos foi de fato a primeira apresentação breve do trabalho experimental de uma maneira sistemática que tenha sido tentado (...) Uma revisão dos Fundamentos poderia ter se tornado um manual de grande importância no começo do século XX” (Flugel, 1964, p. 127). Infelizmente, Oswald Külpe morreu em 1915, com a idade de apenas 53 anos, na epidemia da influenza.

Bühler publicou postumamente a nova edição dos Fundamentos mostrando várias mudanças nas opiniões de Külpe, e mostrando também um sistema bastante bem elaborado. Porém, o que estava faltando era exatamente o capítulo sobre o pensamento! Bühler disse que Külpe não deu aula sobre esse assunto.

Conseguiu-se apresentar as hipóteses de tendência determinante e de pensamento sem imagens. A primeira tinha um lado negativo enquanto afirmava que as condições essenciais dos processos conscientes eram não-conscientes, e um lado positivo, colocando o problema fora da introspecção, exigindo para a pesquisa do pensamento uma profunda preparação do sujeito do experimento. Durante vários anos, sua descoberta de pensamento sem imagens foi considerada uma contribuição completamente negativa. Külpe estava consciente de que o assunto estava se desenvolvendo, mas ainda não tinha chegado à maturidade, e estava muito preocupado em terminar o que ele mesmo julgou ser seu melhor livro: $A$ realização. Sempre achou que seus interesses filosóficos podiam perfeitamente ser combinados com seus interesses psicológicos. Parece que nos últimos anos de sua vida ele, através de seu aluno Karl Bühler, chegou a conhecer melhor as publicações de Hüsserl e sua tendência de justificar a fenomenologia e com isto estava mais inclinado a aceitar as idéias de Brentano sobre a experimentação. Em todo caso, conforme a afirmação de Boring, "Külpe mui acertadamente pode ser considerado um dos principais representantes da ‘nova’ Psicologia” (p. 409).

\section{Escolas influenciadas pela Escola de Würzburg}

Com a saída de Külpe de Würzburg, em 1909, este centro praticamente parou as pesquisas sobre o pensamento. No entanto, três outras escolas continuaram trabalhando dentro da linha de pesquisa de Würzburg. Palland (1961), no seu estudo sobre essas escolas, fornece dados mais concretos que resumimos, em seguida, por encontrar pouca literatura disponível a respeito: a Escola de Colônia (com Lindworsky e seus colaboradores, Frohn, Sassenfeld e Schäfer); a Escola de Mannheim (com Selz, Kindler, Hermann, Sand e Andrae) e a Escola de Amsterdã (com Kohnstamm, Kuiper, van de Hoeve, van Veen e Palland).

\section{A Escola de Colônia}

As pesquisas de Frohn sobre o pensamento da criança surda-muda. Frohn pedia que as crianças surdas-mudas lessem a seguinte história: “Joãozinho colocou o chapéu de papai na cabeça, tomou a bengala de papai na mão e disse: 'adeus mamãe; agora eu vou para muito, muito longe'”.

As crianças, na sua reprodução da frase, não conseguiram apresentar objetivamente o conteúdo. Elas deixavamse arrastar pelas imagens mostrando uma hipertrofia do perceptivo-emocional. Não houve nenhuma compreensão daquilo que foi lido. O pensamento estava inteiramente dominado pelas imagens concretas sem nexo. Por exemplo: “O chapéu de papai era comprido. O chapéu de papai na cabeça. A tempestade, o vento, o chapéu de papai embora. O chapéu de papai foi embora. O chapéu de papai estava sujo. Joãozinho limpava o chapéu de papai”.

Num outro experimento, Frohn apresentava uma palavra-estímulo e as crianças deveriam reproduzir o que elas tinham pensado ou imaginado. Ele encontrou duas reações típicas:

(a) uma formação em fileira: palavra-estímulo "borboleta”. Reações: A borboleta está voando. A borboleta está 
sentada numa flor. A borboleta cheira a flor. As borboletas são brancas e amarelas. A borboleta tem quatro pequenas patas. A borboleta tem duas asas.

(b) uma combinação livre: palavra-estímulo "igreja”. Reações: a menina andou na igreja. A menina falou sobre o menino.

Enquanto em (a) o processo imaginativo está ainda preso ao estímulo, em (b) já vale qualquer nexo que faça algum sentido.

Num experimento seguinte, ele pediu que as crianças lessem cinco palavras que, facilmente, poderiam formar uma história. Por exemplo: ladrão, escada, janela, dinheiro, relógio.

Perguntou a uma criança normal o que tinha pensado. Ela contava: "O ladrão sobe a escada, entra pela janela e rouba o dinheiro e o relógio”. A criança surda-muda de 14 anos contava: "O ladrão tinha roubado muitos ovos e dinheiro. O reparador de telhados põe a escada no telhado. O reparador quer consertar o telhado, porque o telhado tem um buraco. Mamãe limpa a janela. As janelas estão limpas. O homem trabalha na fábrica, etc.”

Conclusões: pensar é trabalhar com elementos abstratos, não perceptivos, cuja direção é determinada pelo problema proposto. No entanto, as crianças muito novas, com certo retardo e surdas-mudas, prendem-se ao perceptivo, deixando-se arrastar pela corrente das imagens concretas. Exatamente por esta quantidade de conteúdos perceptivoemocionais, não se vê um pensamento conceitual. A quantidade de imagens freia o pensamento. As crianças surdasmudas não eram capazes de generalizar ou de abstrair; consequentemente, não conseguiram pôr ordem na corrente caótica das imagens. Uma característica do pensamento primitivo é a ausência de generalização e de abstração.

Nas crianças surdas-mudas, o desenvolvimento refreado da linguagem leva à falta de formas de ordenação. Quando estas crianças são instruídas sobre o uso das possibilidades de ordenação que a linguagem oferece, elas chegam a resultados bem melhores, como mostrou uma pesquisa da Dra. Nanninga-Boon (1934) a respeito de "aprender a pensar” com seu filho surdo-mudo de quatro anos.

Os níveis de consciência da Escola de Colônia. Baseando-se sobre as pesquisas de Frohn e outros, como Sassenfeld e Schäfer, chegou-se a elaborar uma Teoria dos Níveis de Consciência.

(a) O nível das imagens individuais, o perceptivo: elas se originam da própria percepção sensorial. É o nível de experiência e vivência perceptiva e está imediatamente ligada ao concreto, por exemplo: a imagem do navio que vi ontem no porto. Este é considerado o nível básico - inferior.

(b) O nível das imagens esquemáticas, o nível intermediário, são imagens mais vagas e gerais. Essas imagens já são menos ligadas à vivência. As imagens originais são parcialmente transformadas em esquemas. Neste nível, já se percebem relações, já se distingue o que é essencial e o que não o é. A imagem geral esquemática do navio é menos concreta, é uma espécie de resumo de um navio ou um bonequinho com cabeça, tronco e quatro traços para braços e pernas; pode ser um resumo de um ser humano.

(c) O nível de conceitos abstratos, que podem ser organizados em categorias sob um conceito superior. O conceito "navio" é sub-ordenado ao conceito "veículo aquático” e este ao conceito "veículo". Neste nível superior, vêem-se no uso das palavras, as funções e as relações das coisas e nele se realiza o pensamento categorial completamente nãoperceptivo. A quantidade de impressões perceptivas que inicialmente forma uma multidão caótica começa a se organizar em categorias: homens e mulheres, animais que andam, e outros que voam ou que nadam; casas, edifícios, igrejas, ruas avenidas e parques. Surge uma visão mais organizada do mundo dos conceitos. O perceptivo desapareceu e começa existir um saber não perceptivo mais flexível, menos preso a detalhes. O pensamento começa a atuar dentro de categorias de ordenação como: causa-efeito, meio-fim, semelhança-diferença.

Todos os níveis desempenham, alternadamente, seu papel na vida consciente. É lógico que o pensamento abstrato se realiza preferencialmente no nível superior; no entanto, pode ser freado por imagens perceptivas. O "pensar" dos surdos-mudos de Frohn se movimenta essencialmente no nível perceptivo. Há um atraso para chegar aos níveis esquemático e abstrato. Por isso, não há nessas crianças uma ordenação categorial o que causa uma multiplicidade caótica de imagens perceptivas na qual não há um rumo e uma ordenação para um alvo. A confusão não cria o alvo problemático que deve ser resolvido ou alcançado.

O pensamento de um adulto normal se realiza geralmente no nível abstrato. Porém, os níveis não são separados, eles se comunicam: pensar não é um permanecer estático dentro de um mesmo nível. Pensar é um processo dinâmico. Tomemos, por exemplo, o trabalho de um carpinteiro ou de uma costureira que continuamente devem percorrer os três níveis na sua atuação profissional.

A mente pode, alternadamente, operar em todos os três níveis. Com um novo problema o pensamento pode “descer” para níveis mais profundos, mais perceptivos a fim de achar uma nova solução ou a fim de verificar a eficiência de uma nova solução. Também o cientista, seguindo o caminho da indução, começa frequentemente com o concreto para depois formular suas hipóteses e, finalmente, chegar a uma nova teoria.

Importância da Teoria dos Níveis de Consciência para a educação escolar. O alvo da educação de um ser humano é chegar a um pensamento fértil e flexível em todos os níveis mencionados. Para alcançar este alvo, uma primeira exigência é que a camada inferior perceptivo-concreto esteja bem preenchida. $\mathrm{O}$ ensino deve começar com o concreto e seus múltiplos aspectos... À criança deve ser dada a oportunidade de entrar em contato com o mundo nas suas múltiplas formas, senão o ensino se degrada em verbalismo sem base concreta. A camada inferior é a terra matriz na qual se enraíza o pensamento. Pestalozzi dirigia todo seu furor contra o “Maulbrauchen” (blá, blá, blá) a respeito de objetos e situa- 
ções que a criança não vivencia. Vários pioneiros de Pedagogia, como Ratke e Comenius, e até Herbart, insistiram na perceptividade, no ensino áudio-visual e no contato com o mundo real. Um pensamento construído sobre o nível esquemático levaria a conceitos errôneos quando não for controlado e confrontado com o perceptivo. Uma criança somente chega a uma atitude crítica de pensar quando pode comparar as idéias abstratas com a realidade perceptiva das camadas inferiores. Essas idéias não são estranhas ao construtivismo dos nossos dias.

Contudo, também é necessário o desenvolvimento das camadas superiores. Um pensamento maduro é um pensamento abstrato que não pode ser substituído pelo processo das imagens perceptivas. O pensamento esquemático já é necessário para um pensamento mais rápido que não se perde em detalhes. Por isso, a criança precisa aprender a manipular as formas ordenadas e categorias para agrupar as semelhanças em conjuntos maiores e poder dominar a multiplicidade de imagens perceptivas. Sem essas formas organizadoras categoriais que permitem a visão mais global da multiplicidade do perceptivo concreto, o pensamento fica sufocado pela multiplicidade desorganizada, como o surdo-mudo de Frohn. Daí fica clara a necessidade de aprender a aplicar as categorias organizadoras, os conceitos superiores. Os veículos podem ser aquáticos, aéreos e terrestres, estes últimos podem ter duas, três, quatro ou mais rodas e os de duas rodas podem ser bicicletas, motonetas, motocicletas ou ciclomotores, etc. Apresenta-se aqui uma das tarefas importantes do ensino da linguagem: ensinar a sub- e supra-ordenar os conceitos. $\mathrm{Na}$ medida em que as categorias se tornam superiores, também se tornam mais abstratas, até alcançar o nível metafísico do ser.

A Escola de Mannheim - as pesquisas de Selz sobre a psicologia do pensamento

Otto Selz, aluno da Escola de Würzburg, foi contratado como docente na Universidade de Bonn e, de lá, foi para Mannheim. Apesar de não ser mencionado por Boring, suas pesquisas constituem um trabalho pioneiro na área do pensamento. Publicou os resultados de suas pesquisas em Über die Gesetze des geordneten Denkverlauf (Sobre as leis do processo de pensamento organizado) e em Die Gesetze der produktiven und reproduktiven Geistestätigkeit (As leis da atividade mental produtiva e reprodutiva).

Selz pesquisou o papel das imagens no processo de pensamento observando a maneira como as pessoas trabalham quando executam tarefas intelectuais. Elas receberam uma palavra-estímulo e deveriam executar a tarefa de procurar um conceito infra-ordenado ou supra-ordenado. As tarefas foram apresentadas em abreviações; parte: de árvore; todo: de camisinha de gás (das lâmpadas a gás). Isto significava que as pessoas tinham de procurar um conceito que representasse uma parte de árvore, e um conceito que representasse uma totalidade em relação ao conceito camisinha de gás. As pessoas deviam fornecer um relatório introspectivo.

(a) Algumas delas chegaram à solução sem nenhuma imagem. Na tarefa "todo: camisinha de gás", uma delas escre- veu: "Li a tarefa e compreendi; imediatamente veio 'lâmpada de gás' como solução, sem experimentar alguma coisa entre um e outro. Também nada posso lembrar de imagens”. Portanto, algumas vezes as soluções se dão sem imagens. Falamos de pensamento não-perceptivo.

(b) Outras chegaram a uma solução sem imagens, mas logo depois veio a imagem como para verificar a solução dada: Todo? Camisinha de gás. Alguém escreveu: "Assim que li a palavra 'camisinha de gás' compreendi sem me preocupar muito com seu significado, e já estava lá a palavra 'lâmpada de gás'. Imediatamente vi alguns fragmentos perceptivos de uma lâmpada nos quais verifiquei se a solução estava certa. Esta verificação consistia em ver uma camisinha de gás na lâmpada. A imagem era apenas muito fragmentária e somente veio depois da solução. Depois eu reagi.” Ficou claro aqui que as imagens perceptivas podem desempenhar uma espécie de controle sobre a solução já encontrada. Apenas em algumas pessoas, a imagem foi um meio para achar a solução, especialmente, quando a tarefa era difícil, de modo que a solução não se apresentava imediatamente. Nesses casos, o tempo de reação era maior. Por exemplo, o fragmento de protocolo "tarefa: contrário de porto" levava à resposta: "Então minha vista percorreu por cima da água e chegou ao mar. Não sei se opticamente cheguei completamente lá, mas estava na direção e tive a consciência: agora chego ao mar. Tão logo cheguei à consciência de mar pensei: espere aí, esta é uma coisa bem contrária a porto. Então, reagi com a consciência satisfeita de uma solução boa”.

Essas pesquisas de Selz mostram que as imagens perceptivas no pensamento têm uma influência bem menor do que Aristóteles e muitos outros depois dele acreditavam.

Há, no entanto, outros experimentos que mostram que a influência dessas imagens pode ter um caráter inibitório, pois a multiplicidade ou a riqueza de detalhes da imagem perceptiva pode refrear o pensamento conceitual. Willwoll, aluno de Karl Bühler, ofereceu às pessoas duas palavrasestímulo; por exemplo, óculos de motorista (muito usado pelos motoristas quando os carros ainda não tinham pára-brisas) - abajur, com a tarefa de dar um conceito geral que incluísse os dois. Ficou claro que as pessoas que recorreram a imagens não chegaram a bons resultados ou chegaram lá somente com dificuldade. "Eu chamei de propósito na minha mente a imagem perceptiva da coisa, na esperança de me fornecer meios auxiliares para a solução. Estas imagens eram muito nítidas; comparei-as visualmente, procurando então realizar uma ligação conceitual entre as dicas”. Apesar dessa tentativa de usar as imagens mais concretas essa pessoa não chegou a uma solução.

Pode-se dizer que não se chega à solução do conceito geral protetor ocular exatamente porque se perde em pormenores perceptivos.

Descrevendo o processo de pensamento, Selz afirma em primeiro lugar que o pensamento é dirigido para um alvo. Ele aceitou a tendência determinante do pensamento proposto por Narziss Ach, rejeitando o pensamento como um processo de imagens, dominado completamente por leis 
associativas e reprodutivas. O pensamento tem um caráter nitidamente teleológico, dirigido a um alvo, impulsionado e dirigido pela tarefa.

O pensar é impulsionado na direção da solução do problema. Mais modernamente, isso pode ter levado à criação do problem space, de Allen Newell (1972), no qual a tarefa problemática estava à esquerda e embaixo da tela do computador, e a pretensa resolução do problema, através de vários passos intermediários, deveria ser alcançada no lado direito, em cima da tela. Seu problema geral era detectar os diversos meios de que a mente lança mão para chegar a uma solução satisfatória do problema, apresentando também a idéia de que estamos resolvendo problemas o dia inteiro. Há alguns que já sabemos resolver imediatamente; porém, para outros, temos de achar os caminhos adequados, o que nem sempre é fácil.

O processo consciente de solucionar o problema é empurrado numa direção, todos os complexos de imagens e conceitos que podem facilitar encontrar a solução podem ser invocados, aqueles que não são eficientes são eliminados e os eficientes são aproveitados.

Conforme Selz, um dos importantes processos da inteligência é a complementação do complexo (Komplexergänzung). Uma série de conceitos que se relacionam de certa forma é considerada um complexo. A tarefa poderá definir ainda mais o complexo: supra-ordenação, infraordenação, semelhança na categoria, etc. A tarefa "todo? quadro" significa que se deve realizar uma Komplexergänzung; é preciso procurar-se um conceito que é uma totalidade em que o quadro se encaixa. Sendo incompleto na fase da tarefa, o complexo tem uma tendência a ser complementado formando uma unidade fechada. Cada elemento do complexo tem a tendência de chamar o todo na consciência. Vê-se nitidamente a influência do Gestaltismo, que desde a segunda década do século XX exercia sua influência.

Outra idéia de Selz foi o esquema antecipante. Desde a colocação da tarefa e sua compreensão consciente, certos métodos adequados de pensamento começam a funcionar. A própria tarefa já determina esses métodos, que são como esquemas que antecipam a solução. Pode-se dizer que a tarefa antecipa a solução na forma de um esquema. Pode-se imaginar isto graficamente como representado na Figura 1.

No momento em que se coloca o alvo intelectual ou a tarefa, não surge uma série de imagens que se associam entre si, como se pensava antigamente, mas começam a se ativar determinados métodos de solução. Dada a tarefa "defina um trapézio”, automaticamente se reage com certo esquema de definição: "um trapézio é uma figura geométrica... com tais e tais características”. Esta teoria de Selz se fundamenta em material experimental bastante extenso.

Vejamos uma parte de um protocolo "todo? quadro". A pessoa responde "Parede; eu tentava ligar ao quadro algo maior do qual o quadro formaria uma parte espacial”. Pode-se ver aqui nitidamente a totalização ou complementação do complexo e há também uma antecipação esquemática do todo do qual o quadro faria uma parte espacial. Por fim, Selz chega

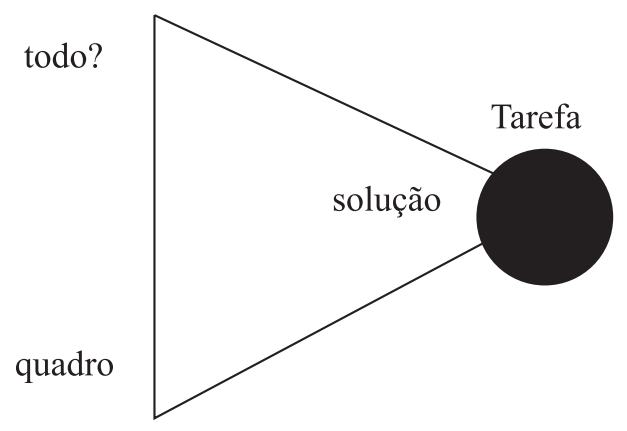

Figura 1. Esquema de antecipação (adaptado de Palland, 1961, p. 401).

então à seguinte conclusão: "pensar consiste na manipulação de uma grande quantidade de métodos de solução”. Meio século depois, Allen Newell (1972) procurou seguir por computador no problem space as sucessivas tentativas para alcançar a solução, incluindo as diversas aprendizagens.

Nós nos servimos de métodos sem sermos conscientes disto. Conforme Palland (1961), Kohnstamm define esse processo da seguinte forma: “aprender a pensar é conhecer e manipular com compreensão os sistemas categoriais de ordenação através dos quais uma multiplicidade de dados perceptivos não-organizada se transforma num todo ordenado e possível de ser dominado” (p. 402). Tais sistemas de ordenação são entre outros: causa e efeito, meio e fim, semelhança e diferença, supra e infra-ordenação, coordenadas espaciais e temporais.

Resta indagar se os métodos de solução podem ser aprendidos. Durante sua permanência na Universidade de Bonn, Selz ocupou-se principalmente em encontrar os métodos de solução. Compreendeu que é importantíssimo para o pensamento criativo tentar conhecer os métodos de solução que são aplicados nas diversas espécies de problemas. No entanto, em Mannheim, ele estudou mais o problema da possibilidade de aprender os métodos de solução: a educabilidade de realizações da inteligência (Die Erziehbarkeit von Intelligenzleistungen). Otto Selz definiu, como descrito por Palland (1961), a questão da seguinte forma: "se para determinadas operações intelectuais achei o método mais eficaz, posso então dar às pessoas que por si só não conseguiram chegar a uma solução uma compreensão do método, de modo que elas possam aplicá-lo com sucesso no futuro?” (p. 402). Selz respondeu a questão afirmativamente, sob a condição de que a pessoa tenha a maturidade necessária para compreender o método.

Diversas pesquisas foram feitas por alunos de Selz a respeito da educabilidade de realizações inteligentes. Assim, Getrud Bauer publicou “Tentativas de definições sintéticas; uma contribuição à questão da educabilidade das realizações inteligentes”. Ela pediu a crianças de 9 a 11 anos para definirem alguns conceitos como: carteiro, casa, sede. Inicialmente, deixava as crianças trabalharem sem nenhuma instrução. Depois, deu algumas instruções sobre a maneira certa de 
definir, através de uma discussão crítica de algumas definições. Em seguida houve uma grande melhora nas definições das crianças. Uma das fontes dos erros era um desenvolvimento grande de imagens.

Sand realizou experimentos com um teste de série no qual crianças portadoras de deficiência mental de 10 a 12 anos tiveram que completar séries como: $1-6-11(\ldots), 3-6-$ 12 (...). Inicialmente, elas também trabalharam sem instrução e os acertos foram da ordem de $16 \%$. Depois de uma explicação sobre o que deve ser levado em consideração para continuar bem a série, os acertos subiram para $67 \%$ com novas séries do mesmo tipo. Em seguida, apresentou séries de um outro tipo e os acertos chegaram a $77 \%$, mostrando que eram capazes de transferir a compreensão a outros métodos como, por exemplo: séries descendentes como 28 - 24 - 20. A conclusão foi de que existe uma formação da inteligência por transferência de métodos de solução.

J. Andrae, aluno de Selz, apresentava às crianças portadoras de deficiência mental um teste de lacunas em branco para preencher. "Num dia quente de verão estava sentado na (...) fresca de uma árvore à beira do Reno". Ele discutia depois com as crianças as fontes dos erros e as coisas às quais elas deviam prestar atenção quando tinham de preencher um espaço em branco com uma palavra. Depois dessa aplicação, os acertos aumentaram consideravelmente. Portanto, houve aprendizagem pela compreensão do método. O curioso foi que essas crianças também tiveram bons resultados em testes de séries, sem nenhuma preparação. A transferência não era devida à semelhança do material, mas à semelhança de método: prestar atenção naquilo que precede e naquilo que segue.

Com base nas pesquisas da Escola de Selz, pode-se tirar a conclusão de que é possível uma transferência de treino, no sentido de que os métodos de solução aprendidos numa área podem ser aplicados em outras áreas. Os experimentos nos Estados Unidos da América que negaram a transferência de uma disciplina para a outra não eram baseados sobre uma compreensão dos métodos de solução, mas simplesmente sobre as disciplinas como tal.

\section{A Escola de Amsterdã}

Esta Escola é principalmente conhecida pelas pesquisas psicológico-didáticas do Nutsseminarium (seminário de eficiência) sob a direção do prof. Kohnstamm. Ele tentou aplicar os resultados das pesquisas da psicologia do pensamento aos problemas da didática. As pesquisas foram feitas em crianças do ensino fundamental e publicadas nas Comunicações do Nutsseminarium.

Depois de uma grande série de experimentos, Kohnstamm, de acordo com Palland (1961), estabeleceu como seu princípio básico: "uma das principais tarefas da escola fundamental é levar seus alunos a aprender a pensar sob sua própria responsabilidade em todas as disciplinas que se prestam para isso" (p. 404).

Para alcançar essa meta, são necessários cinco princípios, ou condições: (a) A criança deve dispor de conhecimento imediatamente acessível, indispensável para um pensamento correto (esses conhecimentos funcionam como pontos de orientação, pontos de apoio e esquemas seguros como, por exemplo: as tabuadas, a posição de continentes, a posição das províncias da Holanda, a seqüência dos meses e dos grandes períodos históricos. Antes de tudo, é necessário que forneçamos às crianças os meios para achar este pronto conhecimento, se tiver sido esquecido: ensinar a usar um Atlas, uma lista telefônica, uma planta da cidade, tabelas e gráficos de censo, etc.).

(b) Deve-se dispor de certo número de conceitos que devem ser mais ou menos ricos. São os instrumentos do pensar. A escola deve prestar plena atenção ao fazer funcionar esses conceitos (é difícil exigir que uma criança tenha idéias completamente desenvolvidas e plenas; as idéias são dinâmicas, elas crescem, se aperfeiçoam e se corrigem. Mas é exatamente o uso constante delas que será a base de muitos julgamentos. A escola deve dar pelo menos os conteúdos iniciais mais corretos. Conceitos como "fronteira, agricultura, indústria, economia, rosa dos ventos, cultura, idade média, renascença, período, governo, senado, temperatura, expandir, tensão, fruto, reprodução e vertebrados devem ser revisados com certa freqüência.”).

(c) A criança deve aprender a conhecer métodos de solução e esquemas de pensamento que lhe permitam pensar corretamente como, por exemplo: causa e efeito, meio e fim, igual e diferente, igual e oposto, leis e normas, conclusão e opinião.

(d) A criança deve ser colocada diante de uma tarefa que impulsiona e dirige o pensamento (dar conhecimento pronto, fornecer conceitos ricos e esquemas de pensamento são preparações necessárias para o pensamento. É a tarefa que dá o impulso e a direção.). O professor deve aproveitar qualquer oportunidade para propor a seus alunos pequenos problemas que eles devem solucionar. Ele pode fornecer nas diversas disciplinas os dados, mas deve incumbir os alunos de tirar as conclusões.

(e) Por fim, deve-se fazer o possível para que a tarefa fique dentro da esfera de interesses da criança.

Estes princípios formulados na segunda metade da década de 1920 não se mostram muito diferentes de orientações mais modernas, a não ser o papel muito importante dado ao professor como transmissor da ciência e pouca ênfase na própria atividade da criança na conquista dos conceitos, esquemas e métodos de solução.

Desde o início, o Nutsseminarium achava que para ser admitido no ensino médio deveria ser pesquisado tanto o pronto conhecimento como a inteligência. Para atender ao primeiro ponto, foram feitos exames de múltipla escolha e de preenchimento de lacunas em branco. Para o segundo, havia a aplicação de testes de inteligência como o Binet-Simon e o Terman-Merrill, apesar de seus conteúdos estarem completamente fora da prática da escola. Estes testes deveriam testar apenas a capacidade intelectual, excluindo a influência da escola. Um colaborador do Seminarium, Dr. T. Kuiper, atra- 
vés de uma pesquisa extensa com alunos do $1^{\underline{0}}$ ano do ensino médio, chegou à conclusão de que o valor prognóstico desses testes de inteligência deixa bastante a desejar. "Quase a metade dos alunos que teve um resultado ruim nos testes, apesar disso, foram promovidos e por outro lado vários alunos que se saíram muito bem nos testes foram reprovados”. Chegou-se, assim, à conclusão de que o teste de inteligência não era o meio de seleção mais adequado.

As publicações de psicólogos ingleses e norte-americanos, como de Ph. B. Ballard, Cyril Burt e Mac Call propuseram a importância de silent reading. Este termo pode ser definido como uma leitura silenciosa, atenta e inteligente de um texto seguido por um controle. G. van Veen escreveu, em 1929, nas Comunicações do Nutsseminarium, um artigo sobre " $\mathrm{O}$ lugar e o significado da leitura silenciosa no ensino fundamental”. Ele disse: "Na escola atual a leitura deve ser considerada a disciplina central, pois esta leitura forma a base de toda a nossa cultura popular. A forma na qual esta leitura é aplicada na nossa sociedade e quase exclusivamente a leitura silenciosa” (citado por Palland, 1961, p. 407). Conforme o autor, o exercício da leitura silenciosa tem duas vantagens:

1. Educar para pensar de maneira autônoma, o que é importante para o adolescente que deixa de estudar depois do ensino fundamental ou somente depois do ensino médio. Van Veen (citado por Palland, 1961), vê na leitura silenciosa o melhor treinamento para aprender a pensar, para "um uso intensivo e bem orientado da inteligência” (p. 407). Ela treina a capacidade de concentração, de combinar dados e de tirar conclusões.

2. Pode servir como um meio para pesquisar se os alunos estão preparados para o ensino médio; um meio para “testar a capacidade intelectual das crianças”. Dessa maneira, o teste de leitura silenciosa se tornou um teste com o qual van der Hoeve, Kohnstamm e Van Veen pesquisaram extensamente na Universidade de Utrecht, e Palland na de Amsterdã.

Nessas pesquisas, os alunos deviam ler um trecho que deixa bastante espaço para a própria iniciativa de pensar e que está dentro da esfera de interesse do aluno. Essa leitura é seguida por uma série de perguntas bem formuladas que exigem um pensar autônomo e cujas respostas não estão imediatamente no texto, que os alunos podem consultar continuamente. Desta forma, chegou-se a determinar um nível de inteligência que um candidato para o ensino médio deveria alcançar.

Como ficou claro, houve uma influência das pesquisas de Selz sobre o trabalho do Nutsseminarium. Por isso suas duas conclusões importantes foram: (1) todo pensar consiste na manipulação de uma grande quantidade de métodos de solução, e (2) é possível educar a capacidade de inteligência através de treinamento nos métodos de soluções.

A inteligência teórica é definida por Kohnstamm (citado por Palland, 1961) como: “a capacidade de se movimentar em situações perceptivas sempre novas usando os esquemas e as abstrações que no decorrer dos séculos foram encontradas pela cultura humana; em outras palavras, ela pressupõe ensino” (p. 408). Portanto, há uma transmissão de cul- tura que depende da escolarização e não se alcança por capacidades herdadas ou por maturação espontânea. Esta tarefa deveria ser cumprida especialmente no ensino da linguagem.

Foi uma das tentativas importantes de Kohnstamm a de ligar a Psicologia dos testes à Psicologia do pensamento. Essa última se concentrava muito sobre a teoria exata do processo de pensamento, sem se preocupar com a aplicação prática. Por outro lado, a Psicologia dos testes estava tão concentrada sobre a prática que não sobrava tempo para elaborar uma teoria mais correta.

Kohnstamm queria unir essas duas tendências com as finalidades de:

1. Desenvolver a didática do ensino fundamental na direção de um melhor treinamento do pensamento também para os alunos que não iriam seguir o ensino médio. Com isso, queria parar a tendência de "entupir" os alunos com uma grande quantidade de conhecimentos estranhos à vida e sem reflexão sobre seu valor. Crianças também são capazes de pensar seguindo a lógica e um meio importante para alcançar isso é a leitura silenciosa.

2. chegar a meios mais eficientes para o diagnóstico da aptidão para o ensino médio. Inteligência não deve ser pesquisada completamente separada da escolarização do candidato. Os dados da Psicologia do pensamento devem se unir a um método mais eficiente de testar a capacidade intelectual do aluno. É inútil tentar elaborar um teste que somente meça a aptidão.

O valor do teste de inteligência depende do grau de instrução, deve-se saber se a pessoa teve a oportunidade de se apropriar de métodos de solução. Somente depois, podese falar de uma inteligência estável. Fora disto, a mensuração da inteligência pode ser enganosa.

Portanto, a opinião de Kohnstamm é a de que não se deve pesquisar a inteligência teórica com um dos dois métodos independentes um do outro; deve-se unir os dois. Isto impõe ao aluno exercitar-se constantemente na leitura compreensiva e silenciosa.

\section{Consideração final}

Apesar de Külpe não conseguir chegar a uma visão mais abrangente do complexo processo de pensamento, foi um iniciador que tentou com métodos relativamente simples e até aperfeiçoados por seu orientandos penetrar experimentalmente num domínio muito ligado a seus interesses filosóficos: o pensamento. As escolas de Colônia, Mannheim e Amsterdã desenvolveram mais suas pesquisas, dirigindo-se tanto para o campo dos portadores de deficiências sensoriais e intelectuais, como para o campo pedagógico e, até, como solução de seleção de alunos para níveis escolares superiores, substituindo os testes psicológicos de inteligência por provas de compreensão de leitura. Foram as pesquisas geniais de Piaget no campo do desenvolvimento epistemológico da criança e do adolescente e as tentativas de Newell, Neisser, Vigotsky e muitos outros que fizeram com que a psicologia cognitiva passasse a ser considerada um campo consagrado e muito promissor na ciência psicológica. 


\section{Referências}

Boring, E. G. (1950). A history of experimental psychology. Nova York: AppletonCentury Crofts.

Flugel, J. C. (1964). A Hundred years of psychology. Londres: Methuen.
Nanninga-Boon, A. (1934). Het denken van het doofstomme kind. Groningen: J. B. Wolters.

Newell, A. (1972). Human problem solving. Englewood Cliffs: Prentice Hall. Palland, B. G. (1961). De psychologie na 1900. In M. J. Langeveld (Org.), Inleiding in de Psychologie ( $3^{\underline{a}}$ ed.). Groningen: J. B. Wolters.

Reinier Johannes Antonius Rozestraten, doutor em Psicologia Experimental pela Universidade Federal de Minas Gerais e livre-docente pela Universidade de São Paulo, é professor de Psicologia na Universidade Católica Dom Bosco, Campo Grande, Mato Grosso do Sul. Endereço para correspondência: Rua Amazonas, 1186, ap. 102, Vila Aprazível; CEP 79022-130; Campo Grande, MS. E-mail: reinierr@terra.com.br e reinierr@ucdb.br

Recebido em 04 jun 02 Revisado em 16.abr.03 Aceito em 20.out.03 